\title{
Fire-Retarding Ceiling Panel from Recycled Paper Waste
}

\author{
${ }^{1}$ Frederick Ampah Clement, ${ }^{2}$ Kafui Kwesi Agyeman (PhD), ${ }^{3}$ Harold Awuley Quaye and ${ }^{4}$ Eugene Padditey \\ 1, 2, 3,4 Department of Integrated Rural Art and Industry, Faculty of Art, \\ Kwame Nkrumah University of Science and Technology, Kumasi, Ghana
}

\begin{abstract}
The aim of this paper is the creation of a fireretarding ceiling panel from recycled paper waste. To achieve this, the researchers employed the experimental and descriptive methods of research accompanied by one of the principles underpinning the emotional construction or psychology-based design approach to product design which is liking (similarity and physical appearance). The target population for the study was printing presses and paper waste in Ghana. Printing presses at the Kwame Nkrumah University of Science and Technology (KNUST) and paper waste from these printing presses were the accessible population. Purposive sampling design was employed with interview and observation being the data collection instruments. Primary sources of data were interviewees, some books and some Internet sources. Secondary sources were mainly books and some Internet sources. The major findings of the study include: low level use of paper waste in Ghana for productive purposes, papier-mâché methods, fire-retarding strategies for papier-mâchébased products, and strategies for removing cast papier-mâché ceiling panels from their moulds. The conclusions established that paper waste is a potential material for the production of suitable ceiling panels, that papier-mâché as a method is a means by which paper waste can be recycled for the production of ceiling panels and that fire retarding properties are achievable with mashed paper-based products.
\end{abstract}

Keywords:- Paper Waste, Papier-Mâché, Ceiling Panel, Fire-Retardation.

\section{INTRODUCTION}

There are few ways in which paper waste has been catered for in our immediate environs: dumping, incineration and burning in the open. These have negative implications on the environment and human health. Poorly collected and poorly disposed waste (paper waster included) have led to clogged drains leading to flooding and the attendant maladies like malaria, diarrhoea and typhoid fever. Properly envisioned waste equals food (McDonough, W., \& Braungart, M., 2003) and that paper waste is useful for the production of valuable products like ceiling panels, egg crates, money wrappers and toilet rolls.

According to the United States Environmental Protection Agency (2014), sustainability is based on a simple principle: everything that we need for our survival and well-being depends, either directly or indirectly, on our natural environment. Sustainability creates and maintains the conditions under which humans and nature can exist in productive harmony, that permit fulfilling the social, economic and other requirements of present and future generations. Sustainability is important to making sure that, we have and will continue to have the water, materials, and resources to protect human health and our environment. Recycling on the other hand, is the process of collecting and processing materials that would otherwise be thrown away as trash and turning them into new products. Recycling can benefit your community and the environment. In other words, it is the process of transforming materials into secondary resources for manufacturing new products (HPR, 2012).

According to Owusu-Sekyere, E. et al (2013) Kumasi is the second largest city in Ghana and the capital of the Ashanti region. It covers a total surface area of $254 \mathrm{~km}^{2}$ and accommodated an estimated population of about $1,468,609$ people as at the year 2010. In 1995, the rate of domestic waste generation in Kumasi was estimated at 600 tons per day (Post, 1999). By 2005, one thousand $(1,000)$ tons of solid waste was generated each day in the city; three years later, the Kumasi Metropolitan Assembly (KMA) collected 1,200 tons a day; documents show that 1,500 metric tons of waste was generated in Kumasi each day (KMA, 2010). Out of this amount, an estimated $70 \%$ is collected by private companies and dumped without pretreatment on a sanitary landfill site at Dompoase. The rest (not collected) is usually dumped by individuals in open spaces or in drains. Household waste comprising mainly organic waste is collected without source separation in 120 liter bins, old boxes, buckets and polythene bags. Waste which is described as "unwanted or unusable items, remains, or byproduct or household garbage" (Encarta dictionary, 2009), and poor environmental sanitation contributed to the six (6) out of the top ten (10) diseases in Ghana with malaria, diarrhoea and typhoid fever jointly constituting $70 \%-85 \%$ of out-patient cases at health facilities (Daily Graphic, November 3, 2005: 11).

In order to solve these problems, there is the need for sustainability practice. The essence of sustainability is to help reduce pressure on natural resources and to maintain ecological balance. Sustainability makes use of the four "Rs" (that is Recycling, Reuse, Reduce and Refuse) and led to this study with research question as follows: How can a fire-retarding ceiling panel be made from recycled paper waste? 


\section{MATERIALS AND METHODS}

The study depended mainly on materials such as paper, paper pulp, polyvinyl acetate, wax, wooden mould, alum, emulsion paint, acrylic paint, electricity, water, and gas. The experimental research and psychology-based design approaches were employed. The target population for the study were printing presses, desktop publishing outfits and paper waste in Ghana. Two printing presses and one desktop publishing outfit at the Kwame Nkrumah University of Science and Technology (KNUST) and one sack of paper waste from these printing presses were the accessible population. The purposive sampling method was used because there was deliberate choice of particular people on the basis that, these selected samples typically represented the community for study. This sampling method focuses on particular characteristics of a population that are of interest, which best enabled the researchers to answer the research question posed. Data was collected through interviews and observation.

\section{Production}

The ceiling panels were created through four (4) phases which are conceptualisation, construction of mould, creation of papier-mâché and casting, and finishing. The first phase (conceptualisation) involved two stages: sketching and three-dimensional virtual rendition of sketches to have a visual, virtual foretaste of the intended products. This was facilitated by the use of the Rhinoceros software. The last phase (finishing) had three stages of coating the panel with alum solution (for fire retardation), painting with white emulsion paint and sprinkling with black acrylic paint.

\section{- Phase one: Conceptualisation (Sketching and virtual rendering)}

Four sketches of moulds were made (Figs. 1, 2, 3 and 4). Each idea had two sections: the mould (at the top) and its intended cast piece (at the base). Sketching was by means of pencil and paper with the use of eraser where needed.

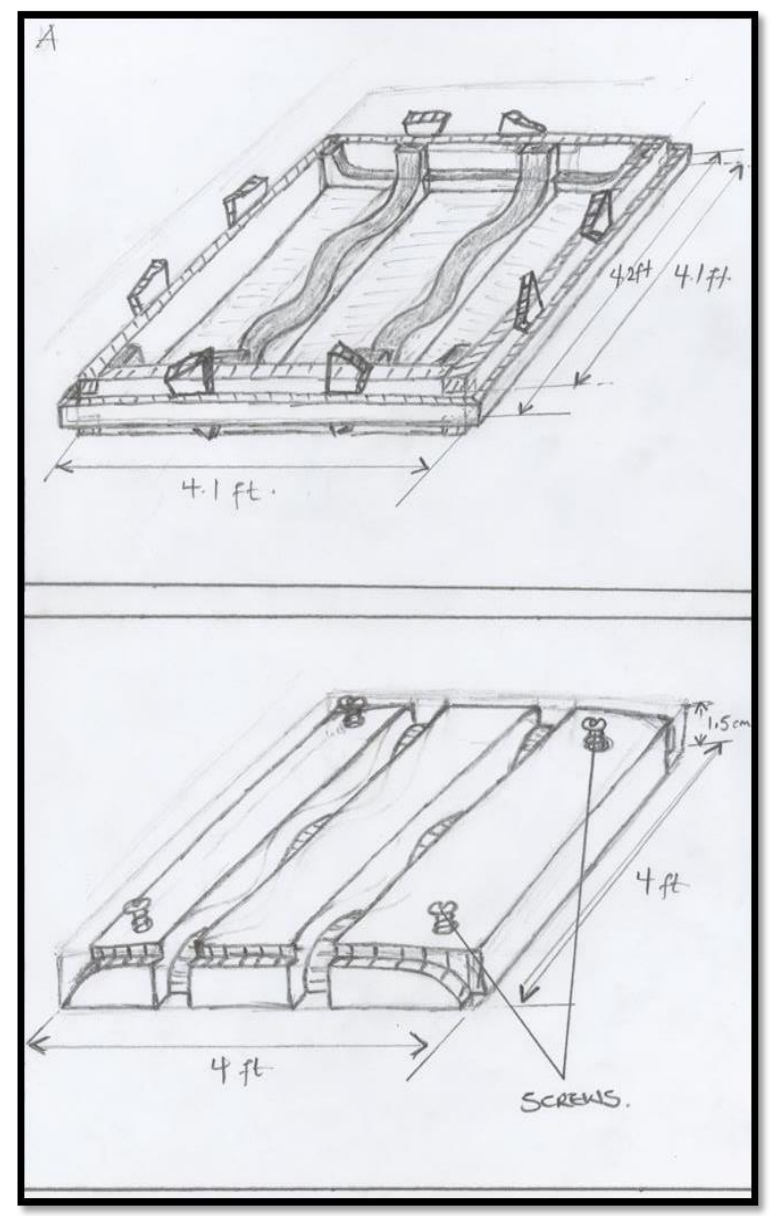

Fig 1:- Mould and cast piece of papier-mâché ceiling panel-Idea one. 


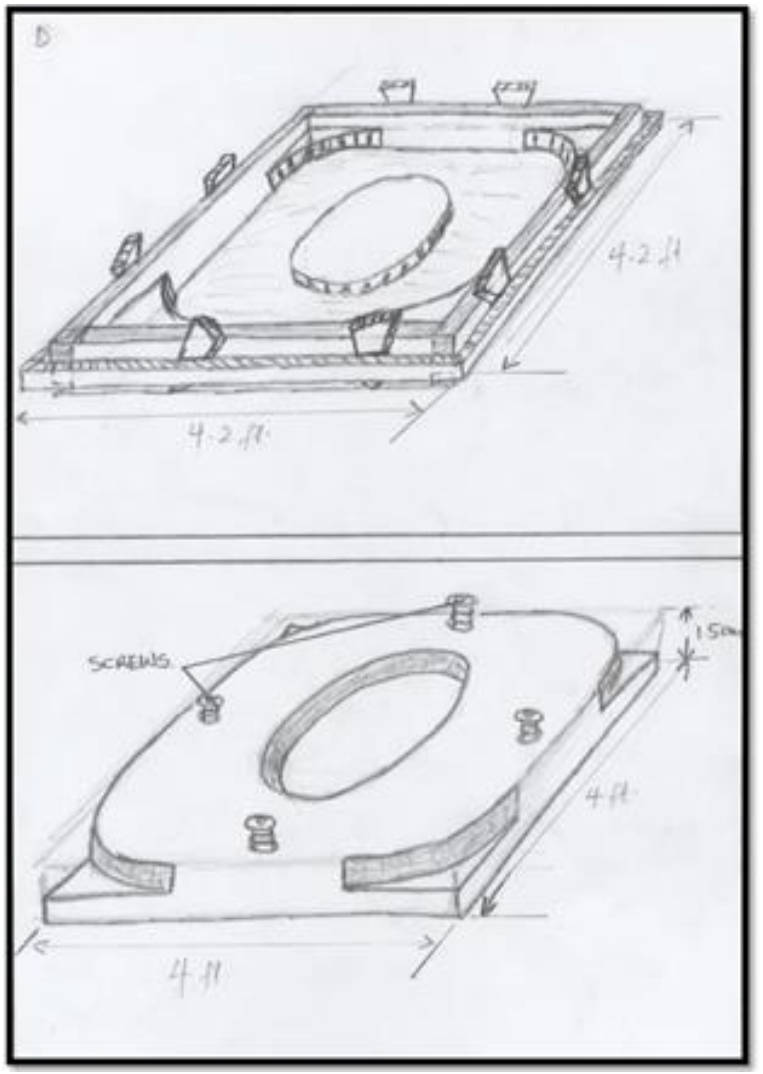

Fig 2:- Mould and cast piece of papier-mâché ceiling panel -Idea two (Selected sketch).

3-D virtual rendition of selected sketch was made using the Rhinoceros software which is for the creation of models in virtual three-dimensional space was used to create the model to have a feel of it in the round as shown in Fig. 5.

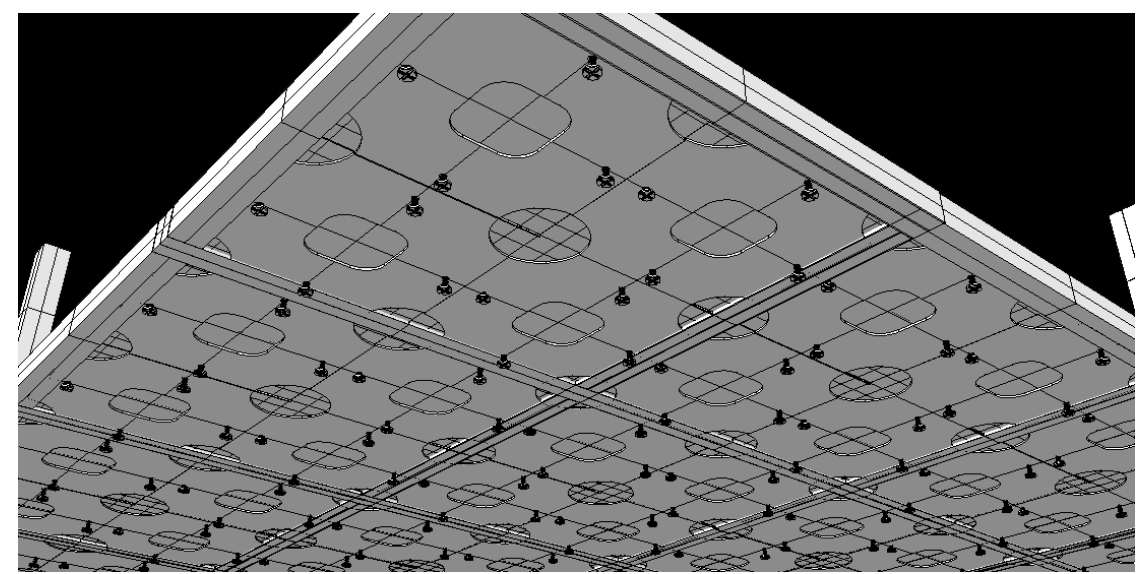

Fig 3:- Three-dimensional virtual model of selected sketch.

\section{- Phase two: Construction of mould}

A two (2) feet by two (2) feet dimension was measured and cut out of a half inch plywood board using saw. The inner patterns for the panel were cut from a plywood board of half-a-centimetre $(0.5 \mathrm{~cm})$ thickness. These patterns were fixed on the 2 feet $\mathrm{x} 2$ feet board by nailing. The essence of the patterns was to give a designed touch to the panel where some parts are in relief, thus, parts are raised and others sunken. An external frame was made from a 1.5 inches square wooden pole and served as boundary to help form the thickness of the cast piece (Fig. 5).

\section{- Phase three: Papier-mâché and casting}

Paper waste was first gathered and soaked in water .The soaked paper were then squeezed by hand to expel water from it and transferred into a mortar and pounded into pulp (Fig. 4). The paper pulp was subsequently mixed with polyvinyl acetate (white glue) for adhesion. The mould was coated with wax to facilitate the removal of the would-be cast piece from it. The mashed paper was gradually poured and pressed into the mould till it was full. The piece was then allowed to dry to get it to separate itself from the mould. 


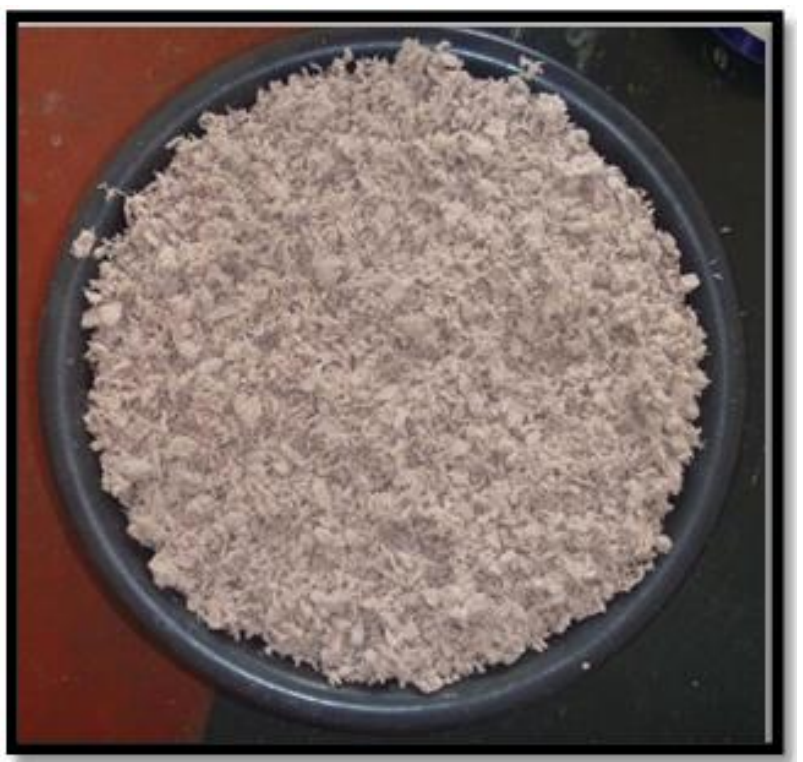

Fig 4:- Paper pulp.

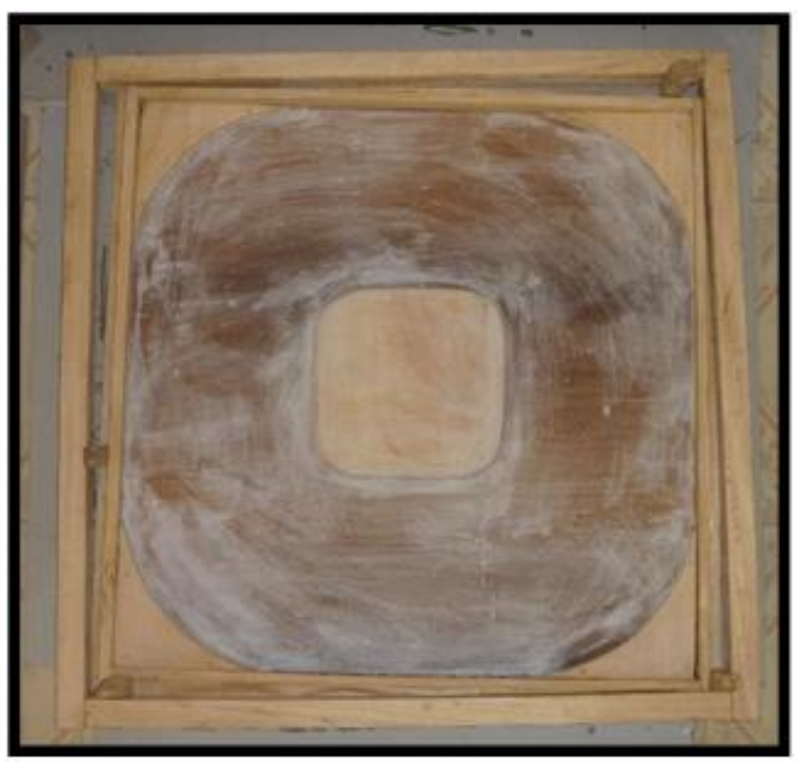

Fig. 5: Coated mould.

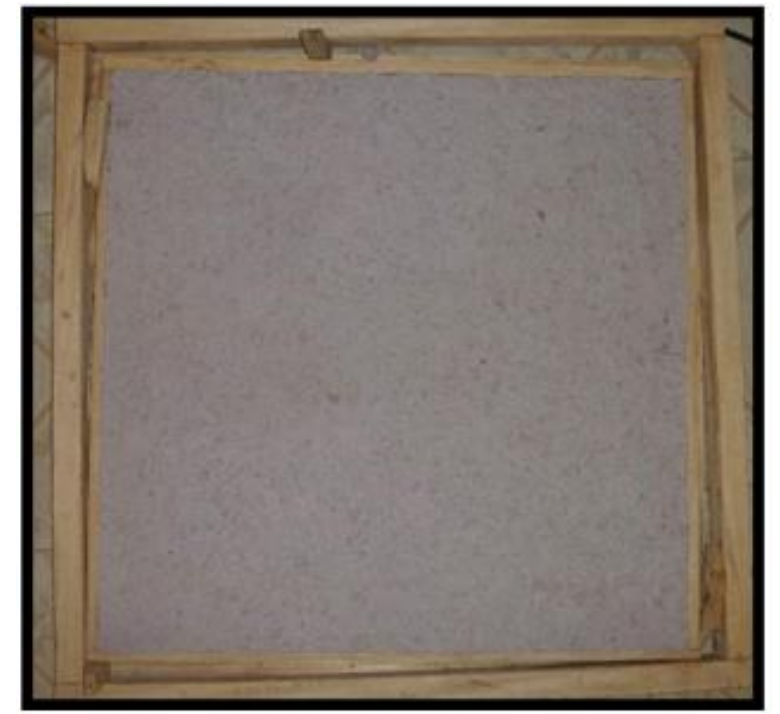

Fig 6:- Full casting. 
ISSN No:-2456-2165

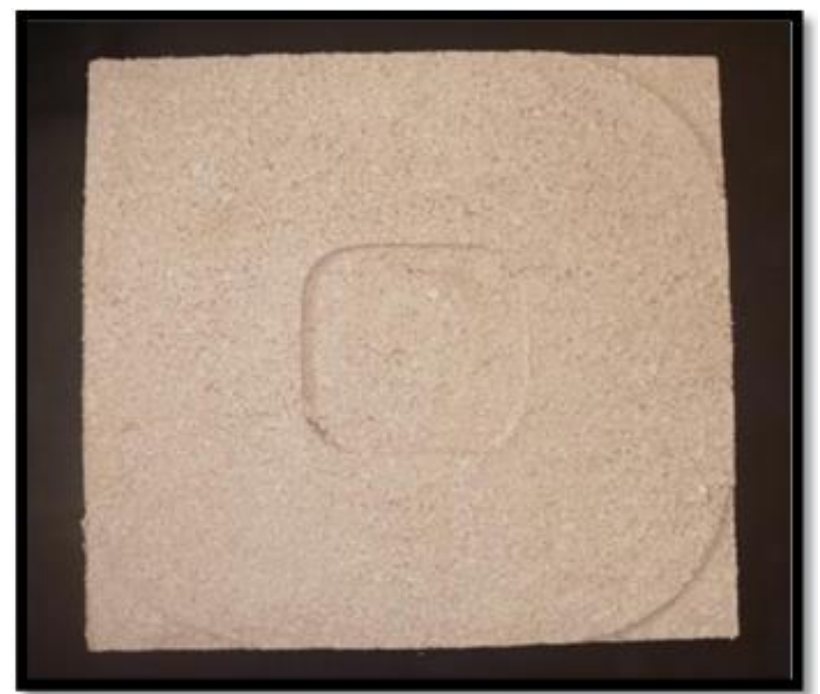

Fig 7:- The cast piece (removed).

\section{- Phase four: Finishing}

The finishing of the piece entailed coating with alum solution (Fig. 9), painting with white emulsion paint, and sprinkling with black acrylic. The essence of the alum solution was to give the panel the property of slowing down combustion during fire outbreak.

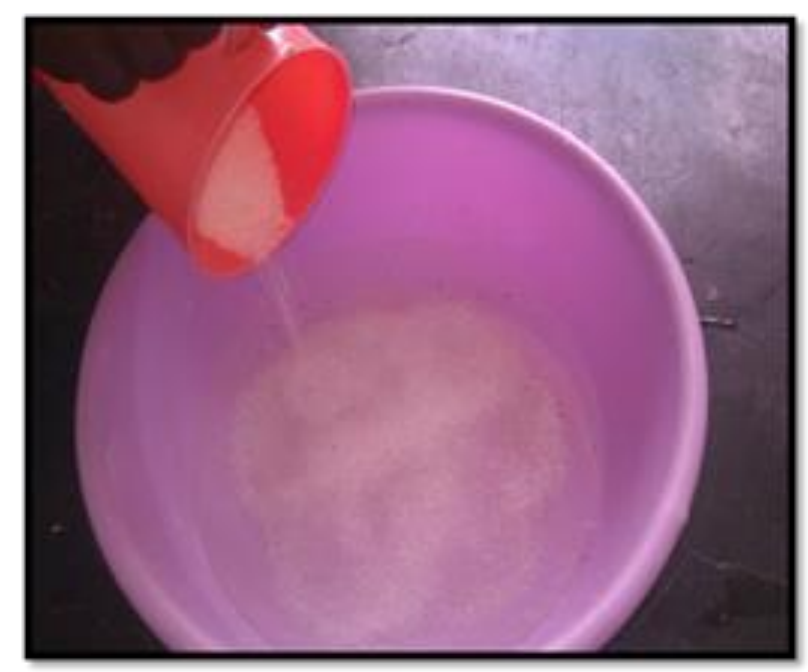

Fig 8: Alum solution.

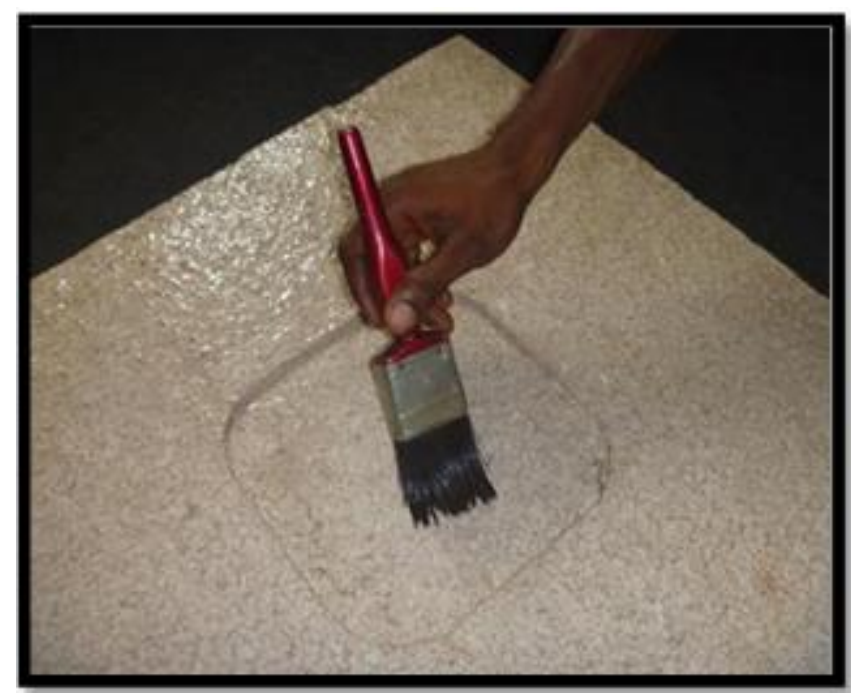

Fig 9: Application of alum solution. 


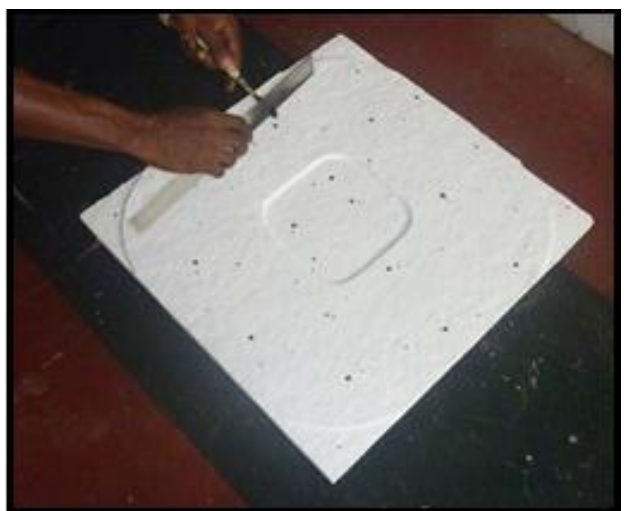

Fig 10: Sprinkling with tooth brush.

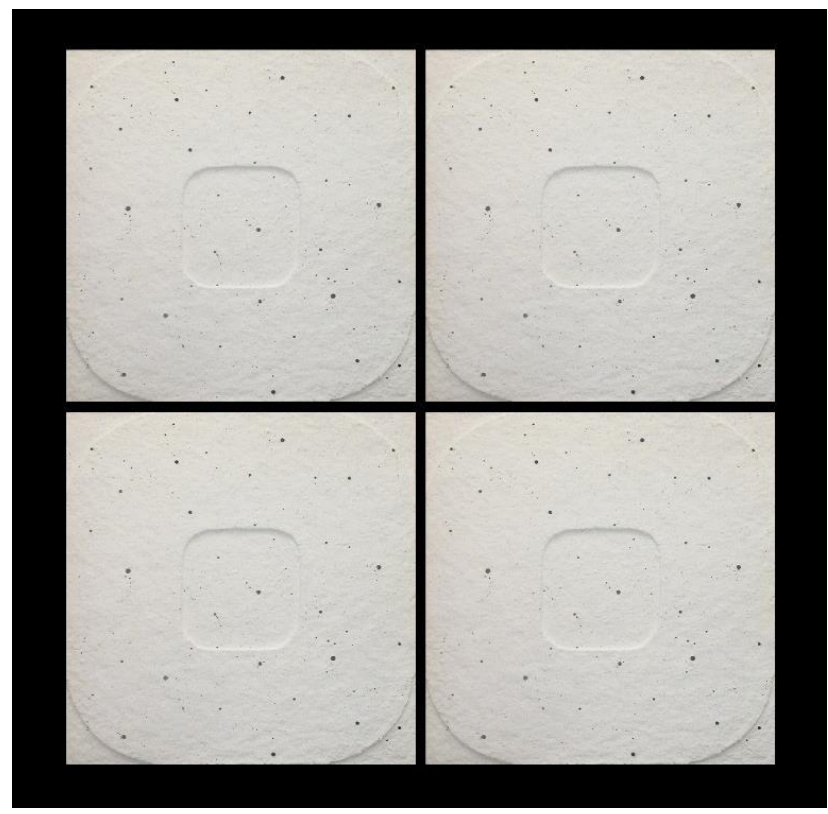

Fig 11: Sample panel.

\section{RESULTS \& DISCUSSION}

\section{Construction and coating of mould with wax}

After the construction of the mould, unwanted gaps in the mould were sealed with a mixture of sawdust and white glue to prevent undesirable shapes in the cast piece and to enhance its easy removal. The mould was then sanded to attain a smooth surface texture. The cast had the tendency to stick to the wooden board upon drying so something had to be done to avoid this, hence, the application of paraffin wax. The wax was melted and applied to the mould by coating with a brush and allowed to dry. In the absence of wax, shear butter can be used.

\section{Paper pulp to glue mixture}

To get a good paper to glue mixture, two plastic bowls which were 14 inches in diameter and 4 inches in depth were filled with the paper pulp and mixed with two-and-ahalf kilograms $(2.5 \mathrm{~kg})$ of polyvinyl acetate (white glue). This mixture when dried became bonded and medium hard keeping the shape of the pieces that form the panel. The pulp- glue mixture should be of good consistency, that is, not too thick or too watery.
$>$ Casting, removal and further drying of cast piece

After casting, the piece should be left for a week for it to separate itself from the mould for easy and safe removal, that is, prevention of breakage. This takes place under room temperature in a room with good sunlight penetration. The drying period depends on the means for drying (normal room temperature, sunlight or oven drying). Sunlight drying is faster with the oven method being the fastest happening in hours. However, good temperature and drying control are critical to keep the panel(s) from being damaged. At this stage, the drying panel should be checked consistently to control warping. Heavy weights should be used in controlling warping to prevent undesirable panel shapes. Panels should be monitored regularly and well positioned to prevent uneven drying or the development of moulds.

\section{Fire retardation}

To achieve this feet, a sample of the papier-mâché was made to the same thickness of the actual panel. Alum was then dissolved in water and applied (coating with brush) to the sample. The sample was exposed to intense fire for 30 minutes. The sample caught fire after approximately five minutes and combusted for the next 
twenty-five. Although the outer part turned completely black, the inner sections were not affected. This experiment proved the slowing down of combustion because of the presence of alum compared to the situation without it.

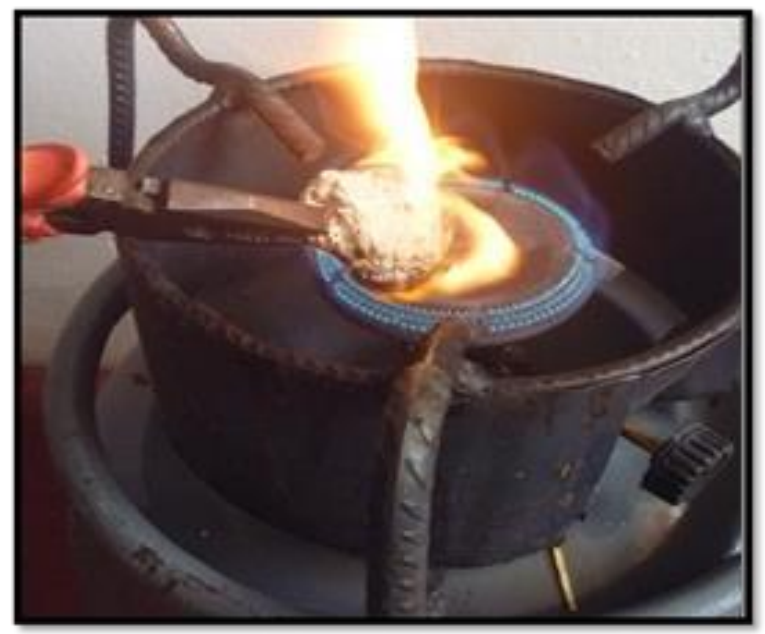

Fig 12: Sample exposed to fire.

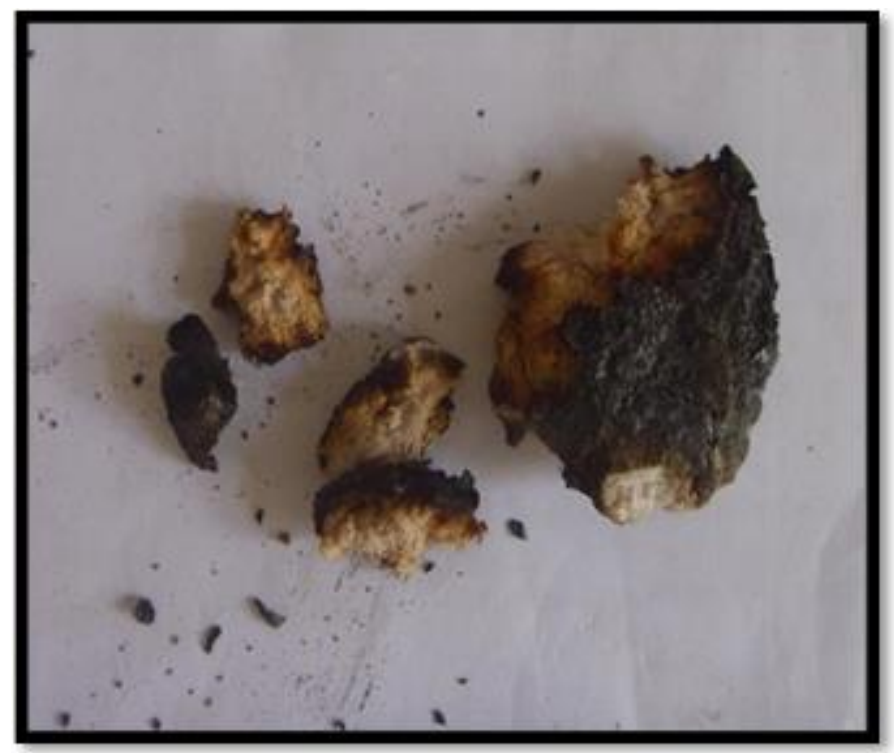

Fig 13: Chipped sample.

\section{$>$ Psychology based design approach}

This approach makes use of the six principles of influence espoused by Cialdini, R. B. (2009) utilised by Tore Gulden, Cathrine Moestue and Arild Berg in their research work presented as conference paper in September 2010. The principles are reciprocity, commitment and consistency, social proof, liking, authority, and scarcity. The principle of liking hammers on four things which lead to humans liking people or things: physical attractiveness, similarity, compliments, and contact and cooperation. This study utilised physical attractiveness and similarity. The panel is physically attractive in the sense that it is simple in colour (black and white) and has a combination of pointed, straight sides and curvy segments. This combination is in tune with the Ghanaian cultural attributes seen in the traditional stool which symbolises male and female attributes, respectively. To this end, attractiveness through simplicity and the cultural dynamism through amalgamation of the male and female qualities makes the panel likeable by the Ghanaian.

\section{CONCLUSION AND RECOMMENDATIONS}

This study explored the creation of fire-retarding ceiling panels from recycled paper waste. It was realised that paper waste can be put to relevant and profitable uses, one being the creation of ceiling panels. The ceiling panels were created through four (4) phases which are conceptualisation, construction of mould, creation of papier-mâché and casting, and finishing. The first phase involved two stages: sketching and three- dimensional virtual rendition of sketches facilitated by the use of the Rhinoceros software. The last phase had three stages of coating the panel with alum solution (for fire retardation), painting with white emulsion paint and sprinkling with black acrylic paint.

It was realised that the panels could be made waterproof and to achieve this it is recommended that Enamel paint be used in coating the back side of the panel. Additionally, before and during casting one must be mindful of prolonged soaking of the paper waste in water because it affects its physical properties and makes pounding difficult: the papers become too soft making them stick together and to the pestle. Excessive water in pulp should be avoided which leads to prolong drying periods and excessive shrinking of the cast piece. Inadequate polyvinyl acetate (white glue) in the mixture leads to poor adhesion of paper pulp and reduces the strength of the panel.

\section{ACKNOWLEDGEMENTS}

Appreciation goes to the following persons for their invaluable work and input: Kwame Prah Garbrah, Joshua Asare, and Basil Cudjoe. Sincere thanks go to you.

\section{REFERENCES}

[1]. Cialdini, R. B. (2009). Influence: Science and Practice. Boston, USA, Pearson Education, Inc.

[2]. Daily Graphic (2005). Daily Graphic, Saturday 26 April, 2005, Accra, Ghana, pp. 21-28.

[3]. Daily Graphic, (2005). Daily Graphic, 3rd November, 2005, Accra, Ghana, pp 14. Ebenezer Owusu-Sekyer, E. H. (n.d.). Retrieved Febuary 5, 2014, from http://www.ijsciences.com/pub/pdf/V2-201304-17.pdf

[4]. Gulden, T., Moestue, C. et al. (2010). Psychology Based Design Approach (PSYDA): A Pedagogical Concept. International Conference on Engineering and Product Design Education. Norwegian University of Science and Technology, Tronheim, Norway. (September 2010).

[5]. HPR. (2012). Retrieved October 2013, from The History of paper and recycling: http://www.fcgov.com/recycling/pdf/history 
[6]. Kumasi Metropolitan Assembly Waste Management Department (KMA) (2010): Data for purposes of planning waste management intervention programmes, Kumasi Waste Management Department. Kumasi, Ghana.

[7]. McDonough, W., \& Braungart, M. (2003). The Cradle to Cradle Design Framework. 1-21.

[8]. Owusu-Sekyere, E., Harris, E., Bonyah, E. (2013). "Forecasting and planning for solid waste generation in the Kumasi Metropolitan Area of Ghana: An ARIMA Time Series Approach". International Journal of Sciences (2): $69-83$

[9]. Post, J. (1999). The Problems and Potentials of Privatizing Solid Waste Management in Kumasi, Ghana. Habitat International, Vol. 23, No. 2, pp. 201216.

[10]. United States Environmental Protection Agency (2014). Recycling and sustainability. Retrieved May 8, 2014, from http://www2.epa.gov/recycle/recyclingbasics. 